normal in size, and considerable difficulty was experienced in removing false teeth for the purposes of identification.

Superficial burns on exposed parts were common, and in a large number of instances coal dust had been driven into the skin, and had to be scraped off before the typical colouring could be ascertained.

'Tattoo marks were very distinct, and the delineations of certain celebrities could be easily made out at almost first glance.

The features of many of the earlier bodies were swollen, and a sanguineous froth exuded from the mouth and nostrils, and showed the typical coloration.

A small pool of blood was found by the side of one body, and was fluid even after the lapse of thirty hours, and of a characteristic bright pink colour.

Fractures and dislocations of almost every possible variety and description were found, and such was the terrible force of the explosion that some bodies were blown to pieces and the limbs of others evulsed at the joints, even the lower limbs being separated in this way without fracture from the hip-joints.

Most of the bodies were found close to the coal faces, and were for the most part in groups, within 100 yards of the working places. The positions were variable, and many were killed whilst actually at work, and just fell over from the position they were in at the time. Thus many were found actually at the coal face on their knees, hauliers beside their trams, and engine men in their seats. Some had tied mufflers round the mouth and nostrils, others their vests or waistcoats; another had plugged his nostrils with cotton-wool.

There were evidences in some instances that boys had been carried by men before both were overcome. Four men had rushed out in one district arm in arm, and had fallen together about 60 yards from the coal face.

Five bodies were found in the No. 1 North Road under a fall, and recovered five weeks after the date of the explo. sion. They were men working in the Bottanic district, and were seen by the survivors after the explosion happened. One was a master haulier and a man of experience, and probably persuaded four others to accompany him in a bid for safety. These men rushed to their doom, for the No. 1 North Road at the time was heavily charged with after-damp, which entered the narrow passage leading to the Bottanic district, and which convinced the others that escape in this direction was impossible. Inasmuch as there was an equal number of survivors and dead in the district, it is probable that had the five men remained with the others, two at least would have survived. The bodies of these men were greatly mutilated, but one showed unmistakable evidences of carbon monoxide poisoning, and thus the injuries must have happened either after death or whilst he was in an unconscious state from CO asphyxia.

In the West York district four men got within a short distance of the shaft before being overcome, and were at variable distances from the 15 to 100 yards proportionate to their respective strengths. All had fallen forward on their faces, and evidently whilst running. Thus the first body was that of a young man of fine physique, and the fourth that of a boy. Ten others had traversed 600 yards before becoming unconscious on the main road close to the Mafeking return. These were in groups of three, and appeared to have sat together and to have gone off to sleep. Two were on opposite sides of a rail, and appeared to have been leaning against each other. The body of the district overman was about 10 yards in front of this group and out-bye to the Mafeking return, whilst the others were in an in-bye position. He had fallen forward on his face, and it is probable that he was leading this group of men to safety, and, being a man of considerable experience and sound judgement, knew that the critical point along the road would be near the Mafeking return, which conveyed the air from this district towards the upcast shaft. halted his men in-bye to this point, and decided to make a test of his own life, and his fellows were to follow if the glimmer of his lamp was seen to be receding, or that he was to shout to the others. This view is held by his old friends, and is highly probable, for he was a man of fine physique, and could have got as far as the four mentioned above, for these, too, had travelled from the coal face, and several of the group of nine might have reachéd a near point to the shaft as well. Thus, amidst the gloom and horror of a terrible disaster, there were evidences of heroism of the finest description.

I am particularly indebted to Dr. Phillip James, the doctor of the colliery, for much valuable information, and to many of the colliery officials for their courtesy and help.

\section{非residential Addresses}

$$
\text { To THE }
$$

\section{BRANCHES OF THE BRITISH MEDICAL ASSOCIATION.}

METROPOLITAN COUNTIES BRANCH.

\section{SOME OBSERVATIONS ON MODERN VASCULAR PROBLEMS,}

BY FRED. J. SMITH, M.D., F.R.C.P., Physician; London Hospital.

Some two or three years ago Dr. James Mackenzie delivered a lecture in which he stated that physicians had been in the habit of making two fundamental errors in their teaching of the pathology of cardiac disorders; and my first object is to show that these errors existed only in his own mind, and arose from his ignorance of the teach. ing (at any rate at the London Hospital) of cardiology, and from his lack of appreciaticn of the lessons conveyed by the literature of the subject.

His first statement was that we physicians had taught that a valvular bruit heard in the heart invariably meant the commencement of a condition certain to grow worse, was always an omen of dreadful things to come-was, in fact, the handwriting on the wall of a fate from which none of the possessors of a bruit could ever hope to escape. I take this opportunity, belated though it be, of flatly contradicting such a pernicious error of statement.

Evidently Dr. Mackenzie had never had the advantage of hearing the late Sir Andrew Clark speak on the subject. I well know that Clark was constantly teaching that bruits were not always to be looked upon as such dreadful portents, for he had collected (and I believe published) a large number of cases in which in the course of routine examination he had found valvular murmurs without any signs whatever of cardiac insufficiency, cases which he labelled "murmurs without heart disease" and against which he warned us especially to be on our guard lest we should frighten some poor soul into a serious illness. Nor could Dr. Mackenzie have heard of Sutton's teaching. I had the good fortune to be his house-physician, and many is the time I have heard him say, "Gentlemen, it is my good fortune to be a little deaf, so that I cannot always hear these murmurs of which you speak"; and we who knew him were always proud to admit that Sutton with his one ear could hear more than we could with our two, by which we meant that his clinical knowledge could see much farther into the case than our stethoscopes could take us.

These two instances are quite sufficient to show Dr. Mackenzie's ignorance of the teaching of his time, and as an old pupil of these great masters of medicine I must confess to some little soreness at hearing a specialist express in public a disregard for, and ignorance of, their teaching.

The second error of which Dr. Mackenzie accused us has as little foundation in fact as had the first. Dr. Mackenzie says that as he reads books on cardiac disease it would appear that it was taught that back pressure caused heart failure. Having evolved this absurd piece of topsy-turveydom, he then proceeded to hold us up to ridicule for having taught it, and in very grave language to inform us that the horse drew the cart and not the cart the horse-an observation of which I do not believe that any modern physician can be asserted to be ignorant.

I have now relieved my mind of a portion of the indig. nation $I$ have felt at the publication of these statements, which are not only absurd and incorrect in themselves but unjust to the memory of my dead teachers, and must proceed to express my admiration for the extreme beauty 
and precision with which modern cardiology has solved the minute details of many problems connected with the heart. It has laid bare even before our eyes the exact why and wherefore of irregularities of beat, of tachycardia and bradycardia, of many forms of anomalous rhythm, of venous pulsation, of dicrotism, of pulsus alternans, etc., and no doubt las led many to a much clearer understanding of these phenomena; but $I$ beg leave to. doubt whether this showing up of the individual trees instead of a wood is a sight which it is always advisable to put before the eyes of medical students. Each modern discovery in the science of medicine-bacilli in the sputum of phthisis, eosinophiles in the blood of the hosts of parasites, and now heart-block and auricular fibrillation in heart disease-is apt to be uscd as a short cut by students to enable them to dispense with detailed examination of patients by the eye, the hand, and the car; and, indeed, in relation to my present subject, the magic words, "heart-block," "auricular fibrillation," "excessive or high blood pressure," are quite sufficient to conjure with, without any silly inquiries into shortness of breath, indigestion, diminution of urine, oedema of feet, ascites, etc., let alone a general inquiry into the patient's feelings.

It is true that by electric and other cardiograms a very pretty picture of the heart's working can be obtained, and that by a careful analysis, which must be almost microscopic in accuracy, of the picture thus produced, and by then throwing the picture on to a screen, it is possible to make visible to a large class a great deal of what we formerly had to learn by frequent and prolonged personal observation at the bedside, and which then was : not always easy to convey to our pupils. This is, no doubt, a tremendous advantage, and we owe it entirely to modern methods; but as one who has had considerable experience, not only as a teacher but as an examiner, I must again repeat that $I$ think it a mistake to allow a student thus to substitute pictorial representation for bedside observation. Such pictures and their analyses are of the utmost value to men who are already qualified, to those who by observation and clinical experience have obtained some knowledge of the efficiency or otherwise of a patient's heart, and have learnt to observe the symptoms of dis-ease, as Sutton used to spell it in his lectures on pathology. But I have often been brought to feel in the examination room that pietures, macroscopic and microscopic, weights and measures, can be abused as well as used, and that in the hands of students the former is very likely to be their fate; so much has this been the case in my experience that I have been driven to the firm conriction that it would be a good thing if the teaching of advanced medicine of a "university type" (to use the well-known words of the University Commission) were reserved entirely for a post-graduate course to come in between the final examination and a licence to practise, and to be made compulsory for all students before they are allowed to treat patients on their own responsibility. This is the very best time in a student's career for him to appreciate such teaching, just the time when he wants to compare bedside with laboratory work, so that he can take the best of both.

Blood Pressure.

Let me illustrate what I mean by a few remarks on blood pressure. Early in his career the student learns from his physiology teacher that there is such a thing, and he probably sees many beautiful instruments, and perliaps experiments, by which it and its variations are measured. Pharmacology teaches him how it can be increased or diminished by drugs; in the wards cases of cerebral haemorrhage make a great impression on him by reason of their fatality and sad results other than death. He fincls in all probability that in all the cases of cerebral haemorrhage blood pressure is high-above, say, 150-and by a short and easy process of reasoning he is led by a specious short cut to say, If I find a patient, therefore, with a blood pressure of over 150 or 160 , I must try and bring this down with drugs, that I may rescue the patient from a threatened apoplexy.

What a host of fallacies are here within a line or two of print! It is really difficult to mention, let alone to discuss them all.

The first that springs to my mind is the utter and absolute blank ignorance of us all-including the keenest physiological and pharmacological intellects-as to the intricate causes operating through a whole life which have led eventually to this high pressure; and then, again, the same ignorance as to the special purpose that it serves, and has probably for years served, in the economy of the individual-it must have served some good purpose and have been an efficient instrument to that end, or otherwise the life of the individual would long ago have terminated in death or disease; indeed, we have learnt by clinical, not by laboratory experience, that if we lower such pressures in robust individuals by drugs; we are very likely to produce a condition of depression which is only to be relieved by allowing the pressure to rise again to what, for the individual, has become the normal, however widely this may differ from our ideal normal.

Again, let me ask you to think what you know about the means that may be used to bring down and to keep down-there's the rub-any pressure above the normal. We have, of course, the whole group of nitrites-most valuable drugs-to use on an emergency; we have many preparations of iodine and of thyroid gland substance, but so far as I know the effect of all theso is but temporary and ceases very soon after cessation of medication, and assuredly no one can be persuaded to continue to be a lifelong drug taker, especially when the drugs make him feel rather worse than better. Exercise, we are told, in. creases the blood pressure, but obesity that arises from inactivity is, I believe, just as great an infliction as the high blood pressure, not to mention the dyspepsia likely to arise from the same mode of life. Attention to diet and the administration of purgatives may do some good; provided, again, we do not make life a burden, but only the specialist-and he with less reason than most-claims to understand the precise article of diet that is causing the high pressure. The most usual rule is to cut off that article most desired by the patient-a rule, perhaps, not so empirical as might be thought.

As a third point. worthy of notice let me ask you, collectively, what do you know of two things-(a) the direct effect of the nitrites upon all organs other than the blood vessels, and $(b)$ the effect of the lowered pressure upon these same organs? An honest answer would, I think, be, Nothing at all ; and yet unless your practice be guided by clinical experience you will often be tempted into trying to reduce blood pressure by their means. What would you think of a skilled watchmaker who took a dirty dinner-fork with which to. fish out of a very valuable and complicated watch a grain of dirt? Not much, I trow; and yet I wonder whether the nitrites are a much more delicate instrument when thrust into the exceedingly delicate mechanism of the human body.

Another point. Let me draw your attention to the final argument ..in the mind of the man with the sphygmomanometer, "If I don't lower this pressure the arteries which I know are diseased will burst." I suppose there is no escape from the ultimate term of this argument; arteries cannot stand the pressure in them or they would not burst. This, I suppose, must be true, but who knows the condition of every millimetre of every artery? It necds but very little experience in the post-mortem room to convince anybody that diseased and thickened radials may exist with perfectly healthy arteries of the brain and of the heart, and, per contra, that diseased coronaries may exist alone or diseased cerebral vessels; and, with all these doubtful factors, who knows whether he will do more harm than good by reducing or attempting to reduce blood pressure? May it not be that a good pressure in the coronaries is really essential to cardiac efficiency? may it not equally be true that the same pressure is required for the nutrition of cerebral nerve centres? and may we not be on the horns of a dilemma, either one of which has a disaster for a final term? I personally hold very strong views that it may bo so, and when called upon to treat such a case I prefer, if I can, to try to do as little harm as possible-to treat symptoms rather than physical conditions, to help my patient rather than science, for which purpose I have found that mercury and potassium iodide are as good as anything and better than direct vascular alteratives; if syphilis be, as it too often is, at the bottom of the trouble. we are giving a specific remedy, adapted to go to root causes, and if syplilis be not an antecedent factor these 
Arings, possibly combined with a little digitalis, still seem very useful, though I admit I do not know precisely why.

\section{Auricular Fibrillation and Heart-block.}

My address seems to be rather of the nature of a melancholy jeremiad: "Things are wrong; let us not try to put them right lest we make them worse." So I would like in conclusion to turn to what I consider are the real triumphs of modern cardiology, so that I may finish on a more cheerful note, though I may possibly be giving more credit to modern investigators than they would claim for themselves.

'As I understand the matter, cardiac disorders may broadly be divided into two classes: those of which muscular inefficiency is the essential basis and those of which a nervous trouble is the real foundation; symptoms and physical signs alone would scarcely appoar to be quite sufficient absolutely to determine with precision which is the prevailing factor, though the determination of this factor is absolutely necessary for really effective and rational treatment-perhaps I should say for the really satisfactory management-of the patient and his troubles.

I am led to believe that by a careful study of multiple cardiograms and vasculograms it is possible to determine with absolute precision whether a muscular or a nervous faitl requires to be remedied, if remedy be available. This achievement $I$ hold to be a pearl of great price, an invaluable addition to our knowledge, and I would that every medical man should know of it, and even every student; so long as it will not be misunderstood by him and will not lead him into slackness of observation and indifference to the tales of woe poured into his ears by sufferers.

Even this achievement has, however, at present its disabilities; the instruments required to obtain the - gram are expensive, their application requires considerable skill and experience, and the interpretation of the - grams tlremselves is not always easy. May we hope that before long a good deal of this trouble will disappear and that we shall be able to apply the principles to our poorer patients as to our richer ones, who can demand the services of specialists already?

Meantime let us not despair; let us remember what have always learnt and always taught-that bruits and irregularities of rhythm, faintings and other evidences of cardiac inefficiency, in the young at any rate, are not always of ominous significance, and especially let us remember what specialists would have us forget--that in the vast majority of cases brought to us for an opinion as to cardiac capacity, it is quite possible to form a correct estimate from general experience combined with careful observation of the individual.

\section{WORCESTERSHIRE AND HEREFORDSHIRE} BRANCH.

\section{HOW TO INCREASE THE USEFULNESS OF THE BRITISH MEDICAL ASSOCIATION.} BY

JOHN LIONEL STRETTON, L.R.C.P., M.R.C.S., Senior Surgeon, Kidderminster Infirmary and Children's Hospital. Various suggestions have been put forward with the object of improving the position of the British Medical Association, of enliancing its prestige, and increasing its usefulness. The Plymouth Division has given notice of a motion" "That it is desirable for the future that the British Medical Association sloould confine its policy to promoting the scientific and social -welfaro of the medical profession by leaving all medico-political work to be done by some other body formed for such purpose and registered as a "Trade Union,"." and the Brighton Division recommends "That the British Medical Association be transformed into a Federation for other medical bodies formed to safeguard the interests of one or more sections of the medical profession, while allowing all such bodies to continue their separate existence." These and other resolutions tend to show that there is some dissatisfaction with the Association in its present condition.

To us in Worcestershire the state of affairs is particularly disquieting, because we pride ourselves on the fact that our city was the birthplace of the Association. I think that many of our members who have openly expressed theiv dissatisfaction have failed to realize the magnitude of the debt they owe to the Association. If it be admitted that the fight over the Insurance Bill was not so well conducted as it might have been, there can be no doubt that but for the action of the Association the position of the panel doctors would have been very much worse than it is at the present time.

It is true that the six cardinal points were not all secured. Of these, the wage limit always appeared to me of great importance; and although I am assured by some of the panel practitioners that the loss of it is of no moment, I regret that it was not embodied in the bill. The free choice of doctor, which was supposed to be granted, is by no means secured, and the representation of the profession on the Insurance Committees is totally inadequate. The only point really gained was the in. crease in the financial offer of the Chancellor of the Exchequer. The advance from 6s. to 9s. was enough to satisfy a large majority of the profession that the work would be sufficiently remunerative to justify them in accepting service, in spite of the refusal to concede their other demands. It was this decision which prevented the Association from insisting upon further concessions, and, though we may think that it was a mistake, we should in common justice accept the responsibility and not try to blame the Association.

The dispensing of medicines by the chemists was never contested, although I have on several occasions expressed the opinion that it was a matter of the utmost importance. It lias already given rise to difficulties, and will always be a source of trouble and annoyance. Viewed from the lowest standpoint, as a commercial transaction. is it possible that a doctor would provide his patient with inferior medicine? I say without fear of contradiction that his object must always be to get rid of those who consult him in the shortest possible time, and the cheapest way to do this is to prescribe the medicine which he considers best. If he dispenses it himself he has the advan. tage of knowing that the actual drugs he orders are put into the bottle, and, further, that their quality is satisfactory.

In carrying out the campaign a vast amount of gratuitous work was performed by a body of men who have received scant recognition of the services they rendered or the sacrifices they made. Also a large amount of money was expended by the Association, and this must have temporarily crippled its financial position.

Is it fair, now that the first battle has been fought, to say that no fight was put up? Is it fair to decline a membership which would assist in discharging the bill, or to grumble at a small increase in the subscription to aid in strengthening our depleted finances?

It appears to me that, instead of resigning membership ourselves, it is the duty of each one of us to use our best efforts to obtain reinforcements for the Association by inducing those to join who have hitherto held aloof. For my own town, I am happy to be able to state that since the passing of the Insurance Act I have secured the adherence of the only two practitioners who were outside our fold, so that we now represent a united family.

The suggestion of a federation has some attraction for me. To join up the various bodies which safeguard ou: interests would have distinct advantages. One annual payment would save us the trouble, and possible neglect, of multiple subscriptions; there would be a considerable saving of expense, and the linking together of our scattered forces would strengthen all of them.

To confine the Association to scientific work would, I think, be a mistake. It has a very large membership; it is the acknowledged mouthpiece of the profession; and, as such, it is the orly body at present capable of representing us. It would be a long time before any new organization could occupy such an influential position.

With regard to a "trade union," there is much to bo said on both sides. The idea is repugnant to the pro fessional sense of some of our members, contrary to the traditions which are their pride, and ill accords with their conception of the honour and dignity of our great calling. With all this feeling $I$ agree, but I cannot shut my eyes to the fact that the great cause of wealness in nur ranks is our individualisni. 